On the need of improved Accelerated Degradation Protocols (ADPs) examination of platinum dissolution and carbon corrosion in half-cell tests

Pizzutilo, E.; Geiger, S.; Grote, J. P.; Mingers, A.; Mayrhofer, K. J. J.; Arenz, Matthias; Cherevko, S.

Published in:

Electrochemical Society. Journal

DOI:

10.1149/2.0731614jes

Publication date:

2016

Document version

Publisher's PDF, also known as Version of record

Document license:

CC BY-NC-ND

Citation for published version (APA):

Pizzutilo, E., Geiger, S., Grote, J. P., Mingers, A., Mayrhofer, K. J. J., Arenz, M., \& Cherevko, S. (2016). On the need of improved Accelerated Degradation Protocols (ADPs): examination of platinum dissolution and carbon corrosion in half-cell tests. Electrochemical Society. Journal, 163(14), F1510-F1514.

https://doi.org/10.1149/2.0731614jes 


\title{
On the Need of Improved Accelerated Degradation Protocols (ADPs): Examination of Platinum Dissolution and Carbon Corrosion in Half-Cell Tests
}

\author{
E. Pizzutilo, ${ }^{\mathrm{a}, \mathrm{z}}$ S. Geiger, ${ }^{\mathrm{a}}$ J.-P. Grote,${ }^{\mathrm{a}, *}$ A. Mingers, ${ }^{\mathrm{a}}$ K. J. J. Mayrhofer, ${ }^{\mathrm{a}, \mathrm{b}, \mathrm{c}, * *}$ M. Arenz, ${ }^{\text {,ee }}$ \\ and S. Cherevko ${ }^{\mathbf{a}, \mathbf{b}, \mathrm{z}}$
}

\author{
${ }^{a}$ Department of Interface Chemistry and Surface Engineering, Max-Planck-Institut für Eisenforschung GmbH, \\ 40237 Düsseldorf, Germany \\ ${ }^{b}$ Helmholtz-Institute Erlangen-Nürnberg for Renewable Energy (IEK-11), Forschungszentrum Jülich, 91058 Erlangen, \\ Germany \\ ${ }^{c}$ Department of Chemical and Biological Engineering, Friedrich-Alexander-Universität Erlangen-Nürnberg, \\ 91058 Erlangen, Germany \\ ${ }^{d}$ Nano-Science Center, Department of Chemistry, University of Copenhagen, DK-2100 Copenhagen Ø, Denmark \\ ${ }^{e}$ Department of Chemistry and Biochemistry, University of Bern, 3012 Bern, Switzerland
}

\begin{abstract}
In this work we employ the advanced scanning flow cell based analytical techniques, viz. inductively coupled plasma mass spectrometry (SFC-ICP-MS) and on-line electrochemical mass-spectrometry (SFC-OLEMS) to directly detect the amounts of dissolved platinum and evolved carbon dioxide in two protocols that are commonly used in the fuel cell community to simulate load cycle and start-stop conditions in proton exchange membrane fuel cells (PEMFCs). In contrast to previous assumptions, claiming a separation between carbon corrosion and platinum dissolution, in both standard protocols platinum dissolution and carbon corrosion are present at low rates, which is also reflected by a comparably low ECSA decrease. On the other hand, a huge increase in rate of both processes is observed during transitions from low to high potential regimes experienced by a PEMFC in operation, here studied in a third protocol covering the whole potential range from 0.6 to $1.5 \mathrm{~V}_{\mathrm{RHE}}$. The latter is typically not addressed in literature. This finding is explained by taking into account platinum catalyzed carbon corrosion and transient platinum dissolution. Based on the obtained results, the question is raised on the practical adequacy of the standard protocols for differentiation of degradation processes and simulation of the degradation processes occurring in PEMFCs.

(C) The Author(s) 2016. Published by ECS. This is an open access article distributed under the terms of the Creative Commons Attribution Non-Commercial No Derivatives 4.0 License (CC BY-NC-ND, http://creativecommons.org/licenses/by-nc-nd/4.0/), which permits non-commercial reuse, distribution, and reproduction in any medium, provided the original work is not changed in any way and is properly cited. For permission for commercial reuse, please email: oa@electrochem.org. [DOI: 10.1149/2.0731614jes] All rights reserved.

(cc) BY-NC-ND
\end{abstract}

Manuscript submitted August 16, 2016; revised manuscript received October 27, 2016. Published November 5, 2016.

All-electric vehicles based on hydrogen powered proton exchange membrane fuel cells (PEMFC) are considered a green alternative for conventional combustion engine driven cars. ${ }^{1}$ Numerous research reports, however, show that life expectancy of fuel cells may be an issue in the way of their successful commercialization. Fuel cell longevity strongly depends on the durability of the cathode catalyst layer, which, in state-of-the-art PEMFCs, is based on carbon supported nanoparticulated platinum $(\mathrm{Pt} / \mathrm{C})$ or platinum alloys. Two primary mechanisms of the catalyst layer degradation are platinum dissolution and carbon corrosion. $^{2-6}$ Current research effort is to suppress both of them by screening numerous alternative materials. In order to minimize experimental time and save costs, these experiments are often done in a half-cell rotating disk electrode (RDE) configuration. In such tests the indirect measure of catalyst degradation is electrochemical surface area (ECSA) evolution during accelerated degradation protocols (ADP), also called accelerated stress test (AST). Since, both carbon support and platinum based catalyst materials are simultaneously investigated, the question arises which mechanism is governing the observed degradation as both degradation mechanisms contribute to an ECSA change.

In 2011 the US Department of Energy (DOE) durability working group and the Fuel Cell Commercialization Conference of Japan (FCCJ) proposed very similar ADPs, in particular, aiming to differentiate between the different degradation mechanisms. ${ }^{7,8}$ Based on the literature data available until 2011, it was suggested that relatively low potentials during load cycles and high potentials during start-stop cycles are critical for platinum dissolution and carbon corrosion, respectively. Hence, two different ADPs based on repetitive potential steps/cycling in potential windows of $0.6-1.0 \mathrm{~V}_{\mathrm{RHE}}$ and 1.0-1.5 $\mathrm{V}_{\mathrm{RHE}}$ were suggested to quantify degradation due to the two respective

\footnotetext{
*Electrochemical Society Student Member.

**Electrochemical Society Member.

${ }^{\text {zE} E-m a i l: ~ p i z z u t i l o @ m p i e . d e ; ~ s . c h e r e v k o @ m p i e . d e ~}$
}

mechanisms. Re-examination of old literature and, especially, data from the work published in the last five years, ${ }^{9-16}$ however, question the practical adequacy of such ADP approach in separating the degradation mechanisms. Especially critical is the avoidance of transitions from start-stop conditions to load cycles and back, i.e. potential transitions from 0.6 to $1.5 \mathrm{~V}_{\mathrm{RHE}}$ and back in these protocols. ${ }^{17}$ Indeed, Ohma et al. showed that potential excursion up to $1.5 \mathrm{~V}_{\mathrm{RHE}}$ can occur after the introduction of gases at the cathode side of the fuel cell. ${ }^{18}$ It should be noted that, the introduction of system mitigation can prevent fluctuations to high cathode potentials. Hence, a drive cycle test up to $0.95 \mathrm{~V}_{\mathrm{RHE}}$ was suggested recently. ${ }^{19}$ At the same time, as all mitigation approaches increase the complexity and price of the system, highly stable catalysts and supports are still the most desirable goal.

In this work, in addition to traditional ECSA evaluation by halfcell thin-film rotating disk electrode (TF-RDE), we use scanning flow cell (SFC) based techniques, viz. inductively coupled plasma mass spectrometry (SFC-ICP-MS) and on-line electrochemical mass spectrometry (SFC-OLEMS) for a clear differentiation between carbon corrosion and platinum dissolution. Besides the traditional load cycle and start-stop protocols we investigate a protocol concentrating on potential transitions between 0.6 and $1.5 \mathrm{~V}_{\mathrm{RHE}}$, which we call here a "combined cycles" test. It is shown that in contrast to previous assumptions in both traditional protocols simultaneous platinum dissolution and carbon corrosion occurs. Furthermore, it is demonstrated that both degradation mechanisms are significantly accelerated when employing potential transitions between 0.6 and $1.5 \mathrm{~V}_{\mathrm{RHE}}$.

\section{Experimental}

A high surface area commercial Pt/C catalyst (TEC10E50E, loading $46 \mathrm{wt} \%$ ) produced by Tanaka Kikinzoku Kogyo (TKK) is used for the present study as a benchmark material. The initial particle size distribution is narrow around $3 \mathrm{~nm}$. The catalyst powder is dispersed in few $\mathrm{ml}$ of ultrapure water (UPW, $18 \mathrm{M} \Omega \mathrm{cm}$, Millipore) by means 


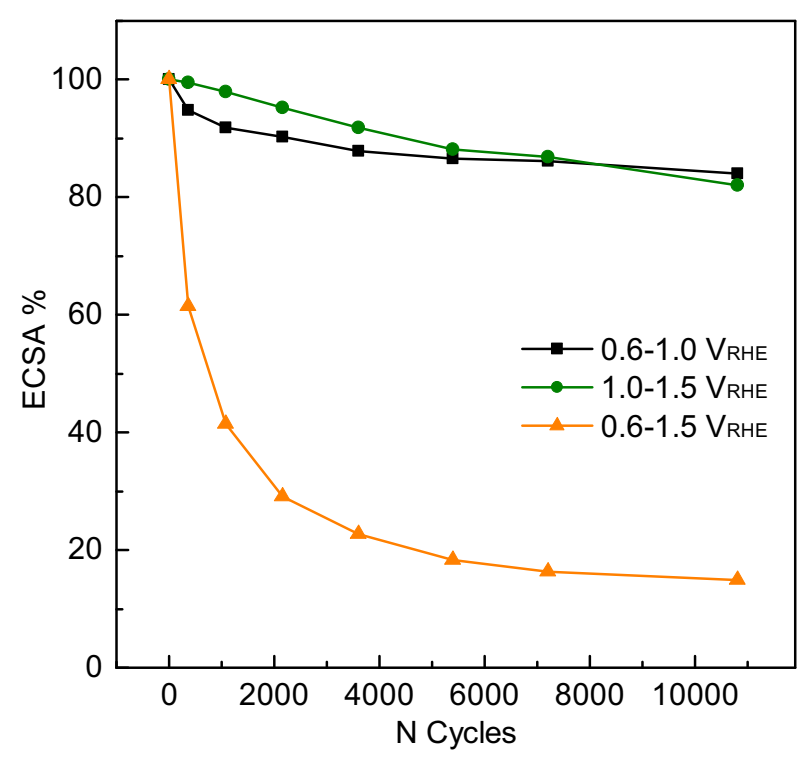

Figure 1. Percentage evolution of the Pt/C ECSA during 10000 potential triangular cycles under the following protocols: 0.6-1.0 $\mathrm{V}_{\mathrm{RHE}}$ (black), $1.0-1.5 \mathrm{~V}_{\mathrm{RHE}}$ (green), 0.6-1.5 $\mathrm{V}_{\mathrm{RHE}}$ (orange). Conditions: Ar saturated electrolyte, room temperature, $0.5 \mathrm{~V} \mathrm{~s}^{-1}$

of an ultrasound bath. After approximately 30 minutes of sonication, a black homogeneous ink is obtained and used for the electrochemical measurement. The catalyst degradation is evaluated under several accelerated degradation protocols (ADP) with a $0.5 \mathrm{~V} \mathrm{~s}^{-1}$ scan rate:

(a) "load cycles" - [0.6-1.0] $\mathrm{V}_{\mathrm{RHE}}$;

(b) "start-stop cycles" - [1.0-1.5] $\mathrm{V}_{\mathrm{RHE}}$;

(c) "combined cycles" test of unified potential range - [0.6-1.5] $\mathrm{V}_{\mathrm{RHE}}$;

(d) "extended combined cycles" - [0.05-1.5] $\mathrm{V}_{\text {RHE }}$.

An in-house built three-compartment, three electrode rotation disk electrode (RDE) electrochemical cell is used to perform the measurement of the electrochemical surface area (ECSA) evolution at room temperature. A small amount of catalyst suspension is pipetted from the obtained black ink and deposited onto a glassy carbon (GC) disc (5 $\mathrm{mm}$ in diameter) embedded in an in-house built Teflon tip (loading of $10 \mu \mathrm{g}_{\mathrm{Pt}} \mathrm{cm}^{-2}$ ). The tip is mounted onto a commercial rotating shaft (from Radiometer Analytical); a graphite rod is used as counter electrode (CE), whereas the reference electrode (RE) is a saturated $\mathrm{Ag} / \mathrm{AgCl}$ electrode (Metrohm). The latter is housed in a separated compartment (Tschurl modification). A Nafion membrane prevents chloride contamination from the separated compartment into the main chamber. The potentiostat (Gamry, Reference600), the rotator, the gases and the ohmic drop are all controlled with an in-house developed software based on LabVIEW environment. The characterization of the ECSA evolution throughout the degradation tests followed a standard protocol, described in our recent literature, ${ }^{20}$ consisting in consecutive CO-stripping after $0,360,1080,2160,3600$, 5400,7200 and 10800 potential cycles ( 8 measuremets at $0.05 \mathrm{~V} \mathrm{~s}^{-1}$ ).

Three accelerated degradation protocols (ADP) with a $0.5 \mathrm{~V} \mathrm{~s}^{-1}$ scan rate are considered: a) load cycles, b) start-stop cycles and c) "combined cycles" test of unified potential range. The RDE was never rotated during the ADPs to avoid additional influence of the rotation to the catalyst degradation. ${ }^{6}$ The electrolyte used is Ar saturated $0.1 \mathrm{M} \mathrm{H}_{2} \mathrm{SO}_{4}$ prepared form the dilution of concentrated sulfuric acid in UPW. From the obtained CO-stripping, corrected from the non-faradaic contribution, the ECSA values are evaluated assuming a surface charge density of $195 \mu \mathrm{C} \mathrm{cm}^{-2}$. These values are then normalized over the initial value yielding the percentage values displayed in Figure 1 in the main text. Prior to the measurement the catalyst is activated until constant cycle voltammograms are obtained.
The Pt dissolution and the carbon corrosion are monitored online during the following protocol: 10 activation CVs [0.05-1.5] $\mathrm{V}_{\mathrm{RHE}}$ $0.2 \mathrm{~V} \mathrm{~s}^{-1}, 300$ load cycles [0.6-1.0] $\mathrm{V}_{\mathrm{RHE}} 0.5 \mathrm{~V} \mathrm{~s}^{-1}, 500$ startstop cycles [1.0-1.5] $\mathrm{V}_{\mathrm{RHE}} 0.5 \mathrm{~V} \mathrm{~s}^{-1}, 200$ combined cycles [0.6-1.5] $\mathrm{V}_{\mathrm{RHE}} 0.5 \mathrm{~V} \mathrm{~s}^{-1}$ and 200 extended combined cycles [0.05-1.5] $\mathrm{V}_{\mathrm{RHE}}$ $0.5 \mathrm{~V} \mathrm{~s}^{-1}$

The SFC-ICP-MS is used to characterize the Pt dissolution. ${ }^{21} \mathrm{~A}$ small amount of $\mathrm{Pt} / \mathrm{C}$ ink is pipetted and deposited on a glassy carbon (GC) substrate forming homogeneous circular spots of approximately $1 \mathrm{~mm}$ in diameter (loading $0.12 \mu \mathrm{g}_{\mathrm{Pt}}$ ). Such spots can be easily approached by the SFC, whose aperture is around $2 \mathrm{~mm}$ in diameter. The electrolyte flowing in the cell is Ar saturated $0.1 \mathrm{M} \mathrm{H}_{2} \mathrm{SO}_{4}$ prepared form the dilution of concentrated sulfuric acid in UPW. The described protocols are carried out with the SFC. Downstream the electrolyte is then mixed with an internal standard $\left({ }^{186} \mathrm{Re}\right)$ and flows into the ICP-MS where the dissolved ions are detected. Thanks to a daily calibration it is possible to precisely evaluate the quantitative $\mathrm{Pt}$ dissolution. As a comparison the measurement is done on a bulk polycrystalline Pt substrate (5 mm Platinum RDE Tip, PINE research) as well.

The SFC-OLEMS is used to characterize the carbon corrosion. ${ }^{22}$ The SFC coupled with OLEMS is slightly bigger than the previous one ( $3 \mathrm{~m}$ in diameter). Therefore also the loading used is higher: $0.48 \mu \mathrm{g}_{\mathrm{Pt}}$ and $0.56 \mu \mathrm{g}$ carbon. The volatile species evolved during the electrochemical measurements (i.e. $\mathrm{CO}_{2}$ ) are collected through a hydrophobic Teflon membrane and flow into the mass spectrometer where they are detected (down to ppb levels). In this case no calibration and therefore no quantitative evaluation have been carried out and only the intensity in arbitrary units is shown. As a comparison, pure Vulcan carbon (Vulcan XC72R) with the same carbon loading is used as well.

\section{Results and Discussion}

Indirectly, catalyst degradation can be quantified by tracking the ECSA change. One of the most elegant ways to measure the ECSA with the TF-RDE is the so-called CO-stripping method, in which the $\mathrm{Pt}$ surface area is estimated from the oxidation charge of a $\mathrm{CO}$ monolayer. As highlighted in the introduction, the PEMFC community accepted as standard the two well-known ADPs for half-cell configuration with potential cycling (square-wave and/or triangular) in the range [0.6-1.0] and [1.0-1.5] $\mathrm{V}_{\mathrm{RHE}}$ for simulating load-cycles and start-stop conditions, respectively. The two half-cell durability tests proposed by the FCCJ consist of triangular-wave "start-stop" cycles $\left(0.5 \mathrm{~V} \mathrm{~s}^{-1}\right.$ scan rate) and of rectangular-wave "load" cycle $(3+3 \mathrm{~s}) .{ }^{18}$ Concerning the latter, the DOE proposed instead to use triangular-wave cycles $\left(0.05 \mathrm{~V} \mathrm{~s}^{-1}\right) .{ }^{23}$ While the degradation depends only slightly on the form of the potential profile, ${ }^{18}$ the time of potential transitions by the scan rate can have a significant impact on the dissolution as well on the ECSA losses. ${ }^{9,24-26}$ For the sake of simplicity only triangular cycles with a scan rate of $0.5 \mathrm{~V} \mathrm{~s}^{-1}$ are employed in this work. In this context, the room temperature performances of a commercial Pt/C PEMFC catalyst are monitored with 8 consecutives CO-stripping during three selected ADPs: the mentioned load-cycle and start-stop protocols, as well as their combination [0.6-1.5] $\mathrm{V}_{\mathrm{RHE}}$ named here "combined cycles" protocol (Figure 1). Note that the CO oxidation was shown to increase the Pt dissolution and thereafter the ECSA losses $;{ }^{27,28}$ however, the impact of $8 \mathrm{CO}$-stripping is negligible compared to the total dissolution during 10000 cycles.

The initial ECSA for $\mathrm{Pt} / \mathrm{C}$, whose average size is $3 \mathrm{~nm}$, is approximately $109 \pm 13 \mathrm{~m}^{2} \mathrm{~g}_{\mathrm{Pt}}{ }^{-1}$. The evolution of the ECSA under the first two protocols is similar and the percentage losses after 10000 cycles (scan rate $0.5 \mathrm{~V} \mathrm{~s}^{-1}$ ) are quite comparable: $\sim 14 \pm 2 \%$ and $\sim 15 \pm 5 \%$ losses for [0.6-1.0] and [1.0-1.5] $\mathrm{V}_{\mathrm{RHE}}$, respectively. The initial faster decrease and the successive plateau observed for the first protocol, might suggest a diverse impact of the degradation mechanisms. Nevertheless, our data shows that the difference after 10000 cycles is not significant when considering the intrinsic error of the 


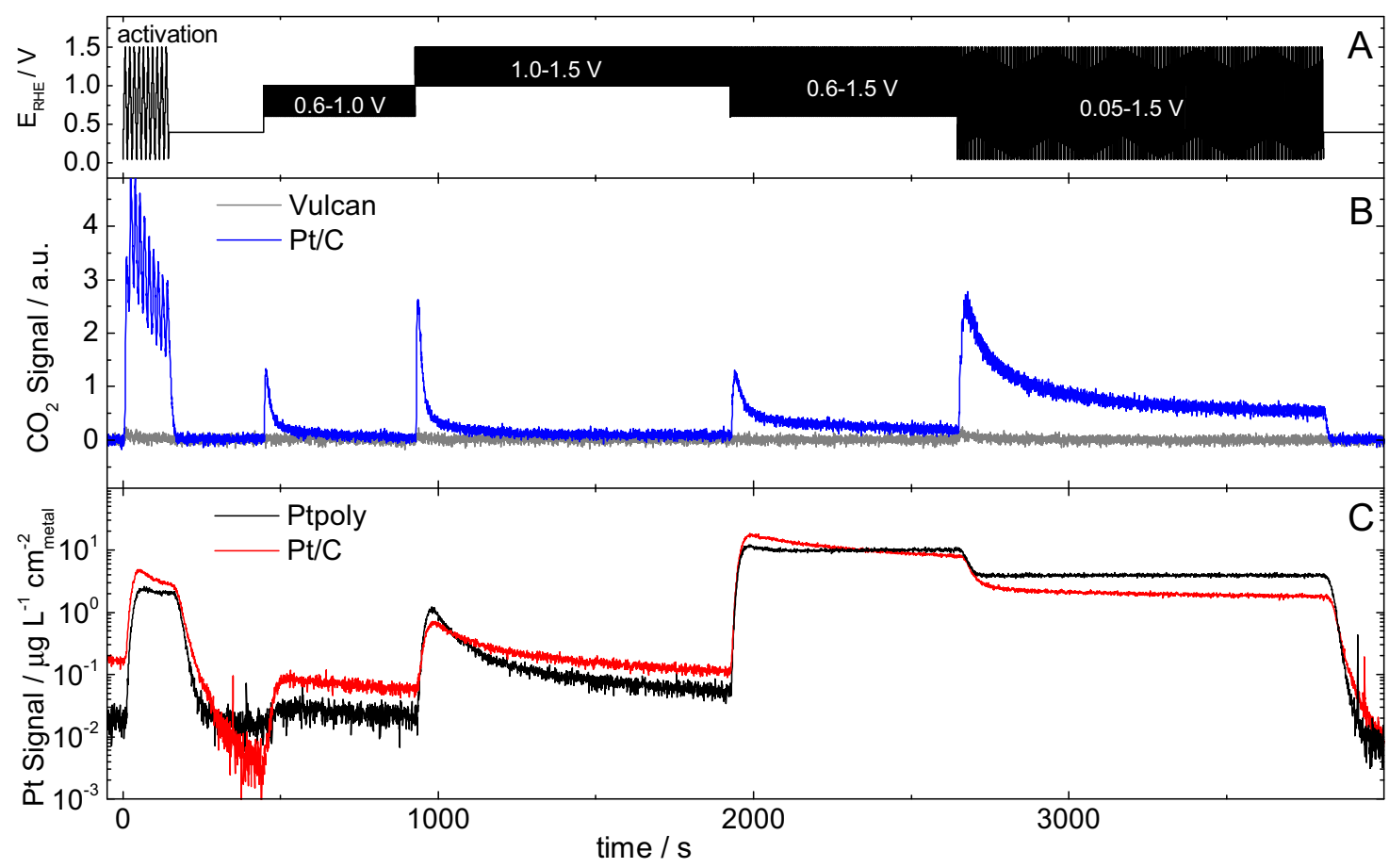

Figure 2. Collection of carbon corrosion and Pt dissolution results in Ar saturated electrolyte at room temperature. (a) The applied measurement protocol consisting of 10 activation CVs [0.05-1.5] $\mathrm{V}_{\mathrm{RHE}} 0.2 \mathrm{~V} \mathrm{~s}^{-1}, 300 \mathrm{CVs}$ [0.6-1.0] $\mathrm{V}_{\mathrm{RHE}} 0.5 \mathrm{~V} \mathrm{~s}^{-1}, 500 \mathrm{CVs}$ [1.0-1.5] $\mathrm{V}_{\mathrm{RHE}} 0.5 \mathrm{~V} \mathrm{~s} \mathrm{~s}^{-1}$, 200 CVs [0.6-1.5] $\mathrm{V}_{\mathrm{RHE}}$ $0.5 \mathrm{~V} \mathrm{~s}^{-1}$ and $200 \mathrm{CVs}[0.05-1.5] \mathrm{V}_{\mathrm{RHE}} 0.5 \mathrm{~V} \mathrm{~s}^{-1}$. (b) Corresponding online $\mathrm{CO}_{2}$ signal (arbitrary units) for the Pt/C (blue) compared to pure Vulcan (gray). (c) Corresponding online Pt dissolution profile for the Pt/C (red) and bulk polycrystalline Pt (black).

measurement. Furthermore, even for longer measurements (up to $15 \mathrm{~h}$ ) only small differences in the ECSA losses between load square wave cycles and start-stop cycles were reported in the literature for a Pt/Vulcan catalyst with a similar loading $(45 \mathrm{wt} \%) .{ }^{29}$ In any case, an investigation on the different on the catalyst nanoscale degradation behavior, which is out of the scope of the present communication, should be addressed in future works.

The "picture" changes drastically under the third protocol, which can be defined as an ADP that covers the potential range of startstop and load cycles - "combined cycles" test. Indeed, the ECSA decreases dramatically: already after 5000 cycles it drops below $20 \%$ of the initial ECSA to stabilize around $15 \%$ after the 10000 cycles. These results already give us an idea of how, compared to the first two traditional protocols, the degradation is accelerated when using a protocol that simulates the transition between the potential regions. Note however, that such a dramatic ECSA decrement is not usually observed in a fuel cell system under real operative condition.

In order to gain a better insight on the underlying degradation mechanisms the dissolution and the carbon corrosion are studied separately (see the profiles in Figure 2 and the amount of $\mathrm{CO}_{2}$ evolved and $\mathrm{Pt}$ dissolved per cycle in Figure 3 ). The catalysts are investigated with the protocol reported in Figure 2a consisting of $300 \mathrm{CVs}$ [0.61.0] $\mathrm{V}_{\mathrm{RHE}}, 500 \mathrm{CVs}$ [1.0-1.5] $\mathrm{V}_{\mathrm{RHE}}, 200 \mathrm{CVs}$ [0.6-1.5] $\mathrm{V}_{\mathrm{RHE}}$ and 200 CVs [0.05-1.5] $\mathrm{V}_{\mathrm{RHE}}$. Prior to any measurement the catalyst is activated with $10 \mathrm{CVs}$ [0.05-1.5] $\mathrm{V}_{\mathrm{RHE}} 0.2 \mathrm{~V} \mathrm{~s}^{-1}$, at the end of which reproducible cycle voltammograms are obtained. The electrochemical measurements are performed in the SFC, whose flexible design allows the online combination with other useful techniques. For example, the $\mathrm{CO}_{2}$ evolution (shown in Figure 2b), corresponding directly to the amount of carbon corrosion, is monitored with the OLEMS. In a separate experiment, the Pt dissolution (shown in Figure 2c) is monitored on-line with the ICP-MS.

OLEMS and/or differential electrochemical mass spectrometry (DEMS) techniques have been commonly used so far to elucidate the mechanism of carbon corrosion on a fundamental level. Single cycle voltammogram studies revealed the influence of crucial parameters (such as degree of graphitization, porosity, presence of plat- inum, etc.) on the carbon corrosion onset potential and on the amount of evolved $\mathrm{CO}_{2} .{ }^{30-36}$ The impact of carbon corrosion under real operative conditions has also been investigated mainly in MEAs. ${ }^{37-39}$ Among them few works focused on the carbon corrosion during extended cyclovoltammetry. ${ }^{40}$ In this context, the carbon corrosion during load-cycles, start-stop, "combined cycles" test, and extended potential range cycles is studied. As a reference pure Vulcan carbon support was measured with the same protocol. In our measurements the $\mathrm{CO}_{2}$ signal is significantly higher once $\mathrm{Pt}$ is present on the carbon surface (blue line in Figure 2b). This catalytic effect is in accordance to earlier reports that showed increase in $\mathrm{CO}_{2}$ evolution and a shift in its onset potential of up to $0.5 \mathrm{~V}$ for the carbon supported $\mathrm{Pt}^{36,41}$ Furthermore, whereas the signal for pure Vulcan exhibits almost negligible deviations from the background signal during the transition between protocols, for the $\mathrm{Pt} / \mathrm{C}$ sample a large peak was observed that is quickly decaying back close to the background level or to a constant value ("steady-state" regime) depending on the applied protocol. Such decay of $\mathrm{CO}_{2}$ signal with continuing cycling has been previously observed elsewhere ${ }^{40,42}$ and has been attributed to catalyst layer degradation ${ }^{37,42}$ and/or to the growth of a protective oxide and thus the inhibition of the corrosion process. ${ }^{40}$ In the case of load cycles $\left([0.6-1.0] \mathrm{V}_{\mathrm{RHE}}\right.$ ) the relatively low upper potential limit (UPL) ${ }^{36,40}$ as well the high lower potential limit (LPL) ${ }^{37}$ can be at the origin of such quick decrease of the $\mathrm{CO}_{2}$ signal. At the same time the prolonged exposure to high potentials can lead to strong Pt oxidation, which consequently becomes much less active for the catalysis of carbon corrosion, ${ }^{41}$ as here for the start-stop cycles ([1.0-1.5] $\left.\mathrm{V}_{\mathrm{RHE}}\right)$. The observed peak in the $\mathrm{CO}_{2}$ signal at the beginning of this protocol is much higher than the previous and it can be tentatively attributed to the transition from low potential regime to high potential regime. After a fast decay the signal reaches values slightly higher than that observed for the load cycles (see Figure 3). On the other hand, during "combined cycles" ([0.6-1.5] $\mathrm{V}_{\mathrm{RHE}}$ ) with the same UPL, the lower potential limit (LPL) is low enough to reduce Pt. Nevertheless, a similar transient behavior is observed, i.e. a strong initial $\mathrm{CO}_{2}$ signal is followed by a slow decay to values higher than both the aforementioned protocols. Interestingly decreasing the LPL even further 

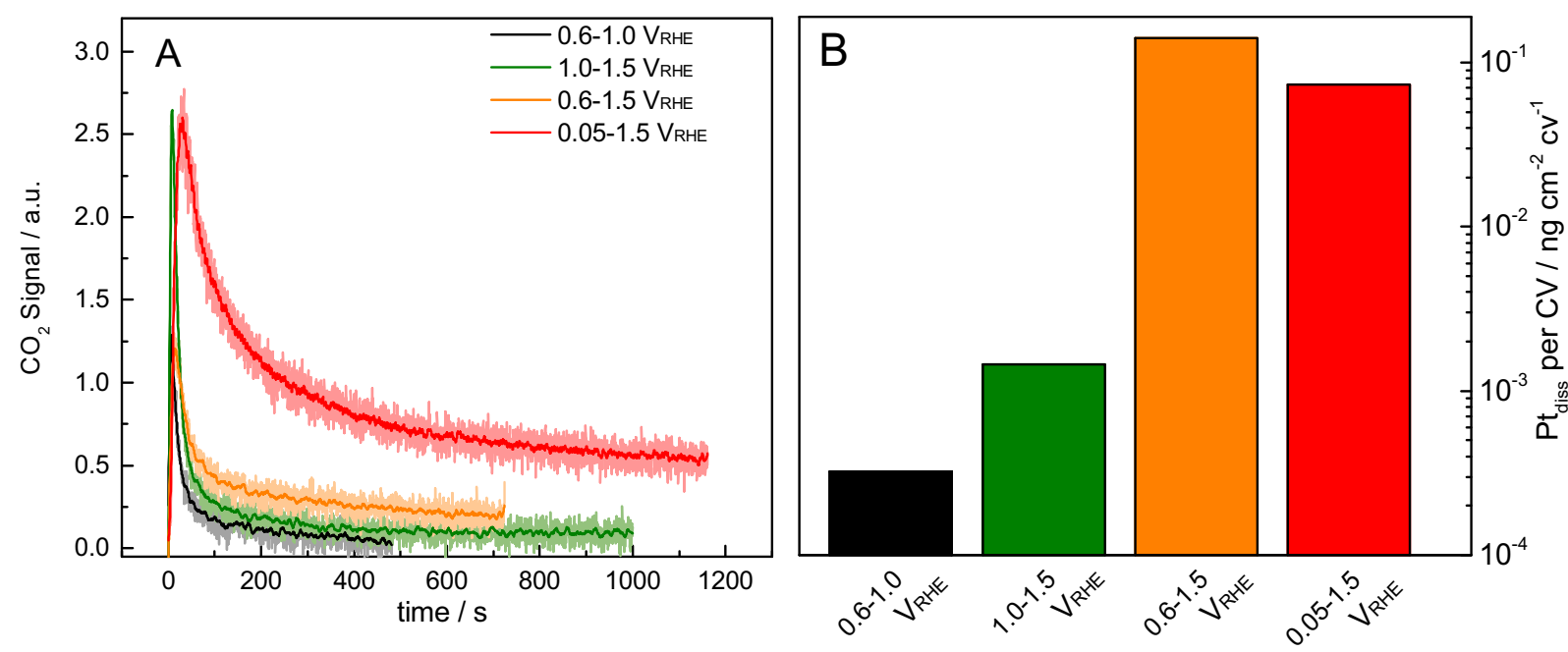

Figure 3. Comparison of the smoothed $\mathrm{CO}_{2}$ signals (a) and of the Pt dissolved (normalized with the number of cycle) (b) corresponding to the different protocols described in Figure 2a, applied to the $\mathrm{Pt} / \mathrm{C}$ sample.

(to $0.05 \mathrm{~V}_{\mathrm{RHE}}$ ), the $\mathrm{CO}_{2}$ signal increases dramatically and a significant, almost constant $\mathrm{CO}_{2}$ signal is observed even at the end of the test cycle. A similar effect was observed independently by Ashton et al. ${ }^{32}$ and Linse et al. ${ }^{37}$ Linse et al. suggested that below $0.6 \mathrm{~V}_{\mathrm{RHE}}$ the changes in carbon corrosion behavior cannot be attributed to the catalytic effect of $\mathrm{Pt}$, which is already reduced. Both authors agree that it can originate from modifications in carbon surface oxide composition. In particular it has been attributed to the destruction of the passivating functional groups on the carbon support, which are formed during initial carbon oxidation. For such process potentials below the standard redox potential of the complete carbon oxidation reaction $\left(<0.207 \mathrm{~V}_{\mathrm{RHE}}\right)$ have to be applied. Thanks to the low LPL, the results obtained for this last protocol are of particular interest for the PEM-FCs anode side, where carbon supported Pt catalysts are as well considered the state-of-the-art catalysts. To conclude it is important to stress that carbon corrosion occurring during the considered ADPs strongly depends on the LPL and UPL as confirmed by other studies on MEAs. ${ }^{19,37,43}$

Besides carbon corrosion, the dissolution rate of $\mathrm{Pt} / \mathrm{C}$ (normalized with the surface area estimated from the last activation cycle) is studied with the online ICP-MS (Figure 2c). As comparison also the dissolution of bulk polycrystalline $\mathrm{Pt}$ is measured. Comparing two electrodes, the total amount of dissolved $\mathrm{Pt}$ is well in agreement for all the applied protocols but the load cycles $\left([0.6-1.0] \mathrm{V}_{\mathrm{RHE}}\right)$ for which the $\mathrm{Pt} / \mathrm{C}$ dissolution is almost one order of magnitude higher than that of polycrystalline Pt. Despite the difference in both cases the dissolution rate is relatively low in this potential range. Indeed, raising the UPL to $1.5 \mathrm{~V}$ ("combined cycles" test [0.6-1.5] $\mathrm{V}_{\text {RHE }}$ ) the amount of dissolved Pt per cycle increases from $0.3 * 10^{-3}$ to $0.14 \mathrm{ng} \mathrm{cm}^{-2}$ $\mathrm{cv}^{-1}$, in accordance with previous studies on Pt polycrystalline..$^{11,44}$ Interestingly, a reduction of the LPL (to $0.05 \mathrm{~V}_{\mathrm{RHE}}$ ) in this case does not correspond to an increase in dissolution, which instead even decreases to $0.07 \mathrm{ng} \mathrm{cm}^{-2} \mathrm{cv}^{-1}$. This difference could be due to the redeposition of Pt that takes place at lower potentials. Recently, Topalov et al. ${ }^{9}$ reported that the dissolution increases steeply by decreasing the LPL from 1.0 to $0.6 \mathrm{~V}_{\mathrm{RHE}}$, whereas only a small dissolution increase was observed upon a further decrease of LPL, apparently in contrast with our results. Nevertheless, in our measurement a much higher scan rate was employed, which could lead to a higher redeposition rate as the Pt-ion diffusion is unfavored. The LPL was also reported to accelerate the ECSA losses. ${ }^{45}$ This is due to the changes with the LPL in the degradation mechanisms, such as carbon corrosion and $\mathrm{Pt}$ dissolution as evidenced by our results. During these three protocols the dissolution is constant for Pt poly, whereas it is slightly decreasing in the case of $\mathrm{Pt} / \mathrm{C}$ due probably to a change in the ECSA expected during the measurement. Conversely, during the start-stop protocol ([1.0-1.5] $\mathrm{V}_{\mathrm{RHE}}$ ) the dissolution profiles decrease for both Pt poly and $\mathrm{Pt} / \mathrm{C}$. After 500 cycles values close to those obtained during load cycles ([0.6-1.0] $\mathrm{V}_{\mathrm{RHE}}$ ) are observed. Indeed, under such conditions, despite the high UPL, the LPL is not low enough for Pt to be reduced. Thus the Pt surface passivates protecting Pt from dissolution. ${ }^{9}$ The low dissolution amount during both load and start-stop cycles explains the similar time dependency in ECSA decrease shown in Figure 1, even though the influence of other degradation mechanisms such as agglomeration and detachment should be as well taken into consideration.

The comparison of the $\mathrm{CO}_{2}$ evolved and $\mathrm{Pt}$ dissolved (the latter normalized by the number of cycles) during the different protocols, are shown in the following Figure 3. This graph summarizes the previously discussed trends in a clear picture: during the classic load and start-stop cycles, the amount of $\mathrm{CO}_{2}$ evolution is relatively low, whereas during "combined cycles" tests it increases significantly, especially when decreasing the LPL to $0.05 \mathrm{~V}_{\mathrm{RHE}}$. Simultaneously, $\mathrm{Pt}$ dissolution is approximately two orders of magnitude higher during "combined cycles" test cycles.

\section{Conclusions}

In this study we investigate the degradation of a Pt/C ORR catalyst in the standard ADPs aiming to simulate the load and start-stop cycles. In literature it is assumed that employing such ADPs in traditional TF-RDE studies it is possible to separate between Pt dissolution and carbon corrosion triggered degradation mechanisms. Following this approach it is found that in both the ADPs the ECSA losses after 10000 cycles are comparable and are around $15 \%$. Significantly higher degradation is observed in a protocol combining both load and startstop cycling. In order to elucidate the $\mathrm{Pt} / \mathrm{C}$ degradation mechanisms in the studied protocols, advanced SFC-ICP-MS and SFC-OLEMS analytical techniques, allowing direct detection (and, hence, differentiation) of $\mathrm{Pt}$ dissolution and $\mathrm{CO}_{2}$ evolution, are employed. It is shown that independent of the protocol Pt dissolution and $\mathrm{CO}_{2}$ evolution are present, questioning the idea of the separation between the two degradation processes on the basis of applied potential window. As an alternative, direct detection of Pt dissolution (e.g. a post-analysis of electrolyte) and/or $\mathrm{CO}_{2}$ evolution can be suggested. Moreover, the obtained rates of both processes are comparably low in the standard protocols, whereas both (especially carbon corrosion) are accelerated in a transition to a new potential region, here simulated also by combined cycles. As an example, the rate of $\mathrm{Pt}$ dissolution is two 
orders of magnitude higher, explaining well the TF-RDE results. These new findings suggest that for comparative tests of catalyst stability, ADPs switching between different conditions, as the combined cycles applied here, should be considered as an important addition to the discussed standard ADPs.

\section{Acknowledgments}

The authors thank the BMBF for the financial support in the framework of the project ECCO2 (Kz: 033RC1101A). S.G. acknowledges financial support from BASF. E.P acknowledges financial support from the IMPRS-SurMat doctoral program.

\section{References}

1. O. Gröger, H. A. Gasteiger, and J.-P. Suchsland, J. Electrochem. Soc., 162, A2605 (2015).

2. J. C. Meier, C. Galeano, I. Katsounaros, J. Witte, H. J. Bongard, A. A. Topalov, C. Baldizzone, S. Mezzavilla, F. Schüth, and K. J. J. Mayrhofer, Beilstein Journal of Nanotechnology, 5, 44 (2014).

3. L. Dubau, L. Castanheira, F. Maillard, M. Chatenet, O. Lottin, G. Maranzana, J. Dillet A. Lamibrac, J.-C. Perrin, E. Moukheiber, A. ElKaddouri, G. De Moor, C. Bas, L. Flandin, and N. Caqué, Wiley Interdisciplinary Reviews: Energy and Environment, 3, 540 (2014)

4. R. Borup, J. Meyers, B. Pivovar, Y. S. Kim, R. Mukundan, N. Garland, D. Myers, M. Wilson, F. Garzon, D. Wood, P. Zelenay, K. More, K. Stroh, T. Zawodzinski, J. Boncella, J. E. McGrath, M. Inaba, K. Miyatake, M. Hori, K. Ota, Z. Ogumi, S. Miyata, A. Nishikata, Z. Siroma, Y. Uchimoto, K. Yasuda, K.-i. Kimijima, and N. Iwashita, Chem. Rev., 107, 3904 (2007).

5. P. J. Ferreira, G. J. la O', Y. Shao-Horn, D. Morgan, R. Makharia, S. Kocha, and H. A. Gasteiger, J. Electrochem. Soc., 152, A2256 (2005).

6. T. Nagai, H. Murata, and Y. Morimoto, J Electrochem Soc, 161, F789 (2014)

7. A. Ohma, K. Shinohara, A. Iiyama, T. Yoshida, and A. Daimaru, ECS Transactions, 41, 775 (2011).

8. S. S. Kocha, in Polymer Electrolyte Fuel Cell Degradation, E. C. Kumbur and T. N. Veziroglu Editors, p. 89, Academic Press, Boston (2012).

9. A. A. Topalov, S. Cherevko, A. R. Zeradjanin, J. C. Meier, I. Katsounaros, and K. J. J. Mayrhofer, Chem Sci, 5, 631 (2014).

10. P. Jovanovič, A. Pavlišič, V. S. Šelih, M. Šala, N. Hodnik, M. Bele, S. Hočevar, and M. Gaberšček, ChemCatChem, 6, 449 (2014).

11. S. Cherevko, G. P. Keeley, S. Geiger, A. R. Zeradjanin, N. Hodnik, N. Kulyk, and K. J. J. Mayrhofer, ChemElectroChem, 2, 1471 (2015)

12. B. R. Shrestha, A. P. Yadav, A. Nishikata, and T. Tsuru, Electrochim. Acta, 56, 9714 (2011).

13. L. Xing, G. Jerkiewicz, and D. Beauchemin, Anal. Chim. Acta, 785, 16 (2013).

14. L. Xing, M. A. Hossain, M. Tian, D. Beauchemin, K. Adjemian, and G. Jerkiewicz, Electrocatalysis, 5, 96 (2014).
15. J. A. Gilbert, N. N. Kariuki, X. Wang, A. J. Kropf, K. Yu, D. J. Groom, P. J. Ferreira, D. Morgan, and D. J. Myers, Electrochim. Acta, 173, 223 (2015).

16. L. Castanheira, L. Dubau, and F. Maillard, Electrocatalysis, 5, 125 (2014).

17. A. Zana, J. Speder, M. Roefzaad, L. Altmann, M. Bäumer, and M. Arenz, J. Electrochem. Soc., 160, F608 (2013).

18. A. Ohma, K. Shinohara, A. Iiyama, T. Yoshida, and A. Daimaru, Polymer Electrolyte Fuel Cells 11, 41, 775 (2011)

19. R. L. Borup, D. D. Papadias, R. Mukundan, D. Spernjak, D. A. Langlois, R. Ahluwalia, K. L. More, and S. Grot, Ecs Transactions, 69, 1029 (2015).

20. J. C. Meier, C. Galeano, I. Katsounaros, A. A. Topalov, A. Kostka, F. Schuth, and K. J. J. Mayrhofer, Acs Catal, 2, 832 (2012).

21. S. O. Klemm, A. A. Topalov, C. A. Laska, and K. J. J. Mayrhofer, Electrochem Commun, 13, 1533 (2011).

22. J. P. Grote, A. R. Zeradjanin, S. Cherevko, and K. J. J. Mayrhofer, Rev Sci Instrum, 85 (2014).

23. Rotating Disk-Electrode Aqueous Electrolyte Accelerated Stress Tests for PGM Electrocatalyst/Support Durability Evaluation, DOE Durability Working group, $10 / 04 / 2011$

24. K. Kinoshita, J. T. Lundquist, and P. Stonehart, J Electroanal Chem, 48, 157 (1973).

25. M. Uchimura and S. S. Kocha, Ecs Transactions, 11, 1215 (2007).

26. M. Uchimura, S. Sugawara, Y. Suzuki, J. Zhang, and S. S. Kocha, Ecs Transactions, 16, 225 (2008).

27. A. A. Topalov, A. R. Zeradjanin, S. Cherevko, and K. J. J. Mayrhofer, Electrochem Commun, 40, 49 (2014).

28. P. P. Lopes, D. Strmcnik, D. Tripkovic, J. G. Connell, V. Stamenkovic, and N. M. Markovic, Acs Catal, 6, 2536 (2016).

29. J. Speder, A. Zana, I. Spanos, J. J. K. Kirkensgaard, K. Mortensen, M. Hanzlik, and M. Arenz, J Power Sources, 261, 14 (2014).

30. K. Artyushkova, S. Pylypenko, M. Dowlapalli, and P. Atanassov, J Power Sources, 214, 303 (2012).

31. S. J. Ashton and M. Arenz, Electrochem Commun, 13, 1473 (2011)

32. S. J. Ashton and M. Arenz, J Power Sources, 217, 392 (2012).

33. O. Wolter and J. Heitbaum, Ber Bunsen Phys Chem, 88, 2 (1984)

34. W. Li and A. M. Lane, Electrochem Commun, 11, 1187 (2009).

35. W. Li and A. M. Lane, Electrochim Acta, 55, 6926 (2010).

36. J. Willsau and J. Heitbaum, J Electroanal Chem, 161, 93 (1984).

37. N. Linse, L. Gubler, G. G. Scherer, and A. Wokaun, Electrochim. Acta, 56, 7541 (2011).

38. K. H. Lim, H.-S. Oh, S.-E. Jang, Y.-J. Ko, H.-J. Kim, and H. Kim, J. Power Sources, 193, 575 (2009).

39. L. C. Colmenares, A. Wurth, Z. Jusys, and R. J. Behm, J Power Sources, 190, 14 (2009).

40. K. G. Gallagher, D. T. Wong, and T. F. Fuller, J. Electrochem. Soc., 155, B488 (2008).

41. V. A. T. Dam, K. Jayasayee, and F. A. de Bruijn, Fuel Cells, 9, 453 (2009).

42. N. Linse, Start/stop phenomena in polymer electrolyte fuel cells, in, ETH (2012).

43. J. D. Fairweather, B. Li, R. Mukundan, J. Fenton, and R. L. Borup, Ecs Transactions, 33, 433 (2010).

44. S. Cherevko, A. R. Zeradjanin, G. P. Keeley, and K. J. J. Mayrhofer, J Electrochem Soc, 161, H822 (2014).

45. C. A. Rice, P. Urchaga, A. O. Pistono, B. W. McFerrin, B. T. McComb, and J. W. Hu, $J$ Electrochem Soc, 162, F1175 (2015). 